\title{
ADAPTASI PSIKOLOGIS IBU HAMIL DALAM PENCAPAIAN PERAN SEBAGAI IBU DI PUSKESMAS KEMBARAN II KABUPATEN BANYUMAS
}

\author{
Wilis Dwi Pangesti \\ Prodi Kebidanan DIII Fikes Universitas Muhammadiyah Purwokerto \\ wilisdwi@gmail.com
}

\begin{abstract}
Pregnancy is a physiological and normal process, not only relates with the biological aspect but also relates to the social, cultural, psychological, emotional, and spiritual aspects of a woman in life. A woman has a task to attain the role of a mother during her pregnancy. There are three stages of adaptation to achieve the role of mother based on trimester of pregnancy. This research aims to describe the physiological adaptation of pregnant women in achieving the role as a mother in the Kembaran II health centre of Banyumas. It is a qualitative research with case study research design. Research subject taken by purposive sampling. The main subject consists of 8 pregnant womens, while the supporting subject is the husband of 8 pregnant womens and 4 midwives in around the research area. Source of research data is the primary data using interview compass. Data analysis using a qualitative analysis techniques with Milles and Huberman's interactive analysis models. The results of this research can be concluded that all of pregnant women in Kembaran II health centre of Banyumas has achieved its role as a mother according to the stage in her pregnancy trimester. There is one condition where pregnant women receive her fetus too early in the first trimester of pregnancy by just looking at the results of a pregnancy test, it's different with previous theory.
\end{abstract}

Keywords: Psychological Adaptation, Pregnancy, Achievement of mother role

\section{PENDAHULUAN}

Kehamilan merupakan suatu peristiwa transisi sosial dan psikologis yang amat kritis. Berdasarkan tinjauan keilmuan, kehamilan merupakan proses fisiologis dan normal, yang tidak hanya berhubungan dengan aspek biologis saja, namun berhubungan dengan aspek sosial, budaya, psikologikal, emosional dan spiritual seorang perempuan dalam kehidupan. Setiap perempuan harus memiliki keyakinan dan pengetahuan yang adekuat untuk bertanggungjawab terhadap diri dan dan janin selama kehamilannya, karena perempuan memiliki tugas perkembangan yang mulia untuk kelangsungan generasi (Underdown dan Barlow, 2012).

Dalam mencapai tugas perkembangan pada masa kehamilan, perempuan melalui tiga fase adaptasi berdasarkan pembagian trimester kehamilan. Pada awal kehamilan, seorang perempuan akan beradaptasi terhadap peran barunya untuk menerima kehamilan dan meyesuaikan diri terhadap peran barunya ke dalam kehidupan kesehariannya. Ia harus bisa merubah konsep diri menjadi calon orang tua. Secara bertahap, ia berubah dari seseorang yang bebas dan fokus pada diri sendiri, menjadi seorang yang berkomitmen untuk memberi kasih sayang pada individu lain. Pada tahap ini, ia memiliki tugas perkembangan untuk menerima kehamilannya meskipun belum ada tanda yang pasti, mengidentifikasi peran baru, dan mengatur kembali hubungannya dengan lingkungan sekitar karena kehamilannya (Bobak et al, 2005; Leifer, 2015; Varney et al, 2007). 
Setelah perempuan merasakan quickening pada trimester kedua, ia mulai mengalihkan perhatiannya ke dalam kehamilannya. Ia menerima janin yang ada dalam kandungannya, sebagai bagian yang tumbuh dan terpisah dari dirinya yang memerlukan asuhan. Waktu dimana perempuan sudah mampu membedakan dirinya dengan janin yang dikandungnya, merupakan awal hubungan peran ibu dan anak yang melibatkan sebuah tanggungjawab. Pada fase akhir kehamilan, seorang perempuan mulai realistis menerima peran sebagai seorang ibu yang mempersiapkan diri untuk melahirkan dan mengasuh anaknya. Perempuan yang positif dalam menerima perannya, akan secara aktif mempersiapkan diri dengan melakukan kunjungan antenatal, berkomunikasi dengan ibu hamil lain untuk memperoleh info yang terbaik tentang peran barunya (Bobak et al, 2005; Leifer, 2015; Varney et al, 2007).

Pencapaian peran sebagai seorang ibu melalui perubahan psikologis dalam kehamilan ini, merupakan tugas seorang perempuan yang harus tercapai, karena jika mengalami kegagalan, dapat memberikan dampak negatif. Depresi dalam kehamilan merupakan salah satu dampak kegagalan pencapaian peran. Kehamilan dengan depresi, selain berpengaruh terhadap ibu, juga mempengaruhi kesejahteraan janin dalam kandungan dengan meningkatkan risiko terhadap pertumbuhan dan perkembangannya, sehingga lahir dengan berat badan lahir rendah (BBLR) dan kecacatan. Kondisi ini dipengaruhi juga oleh gaya hidup, pemenuhan nutrisi dan aktifitas ibu hamil dengan depresi
(Charmichael et al, 2014: 338-344; Burns et al, 2015:247-251).

Pencapaian peran seorang ibu dalam masa kehamilan ini, perlu dukungan keluarga, sosial dan tenaga kesehatan yang luas. Ibu hamil perlu diberikan akses asuhan yang terintegrasi antara fisik dan psikologis, yaitu penerimaan perilakunya, partnership dan konseling. Asuhan yang terintegrasi ini, dapat mendeteksi adanya penyimpangan perilaku psikologis ibu dalam pencapaian perannya, sehingga tenaga kesehatan dapat melakukan penapisan penyimpangan untuk menentukan jenis asuhan psikologis mana yang perlu diberikan. Berdasarkan evidence based, asuhan terintegrasi yang diberikan mulai awal kehamilan, memberikan pengaruh yang positif terhadap kelangsungan kehamilannya di trimester akhir, bahkan sampai proses persalinannya (Lancaster et al, 2010: 5-14; Modh et al, 2011: 1-11).

Berdasarkan data penelitian diatas, kondisi psikologis ibu hamil sangat berpengaruh dalam pencapaian peran sebagai seorang ibu, sehingga dalam masa kehamilannya diperlukan adanya dukungan dari keluarga dan tenaga kesehatan untuk dapat menjalani kehamilannya dengan baik tanpa ada keluhan psikis yang menyertai.

Penelitian ini bertujuan untuk mendeskripsikan adaptasi psikologis ibu hamil dalam pencapaian peran sebagai ibu di wilayah Puskesmas Kembaran II, Banyumas.

\section{METODOLOGI}

Penelitian ini dilaksanakan di wilayah Puskesmas Kembaran II, Kabupaten 
Banyumas, Jawa Tengah. Pelaksanaan penelitian pada bulan Maret sampai dengan September 2016. Metodologi penelitian yang digunakan adalah penelitian kualitatif dengan desain penelitian studi kasus. Desain studi kasus merupakan deskripsi secara komprehensif tentang berbagai aspek individu suatu kelompok atau situasi sosial, dalam hal ini adalah kelompok ibu hamil. Peneliti melakukan penyelidikan secara cermat peristiwa, aktifitas, proses pada kelompok ibu hamil. Informan dalam penelitian diambil secara purposive yaitu dilakukan secara sengaja mengacu pada syarat sampel yang diperlukan (Cresswell dan John, 2009).

Informan utama penelitian terdiri dari 8 orang ibu hamil, sedangkan informan pendukung adalah suami dari 8 ibu hamil dan 4 orang bidan desa setempat. Sumber data penelitian adalah data primer, berupa data hasil wawancara mendalam tentang adaptasi psikologi ibu hamil dalam pencapaian peran ibu yang diperoleh secara langsung dari informan. Pengumpulan data menggunakan metode wawancara langsung dengan menggunakan pedoman wawancara. Analisis data menggunakan tehnis analisis kualitatif dengan model analisis interaktif dari Milles dan Huberman.

Analisis terdiri dari reduksi data, sajian data, dan penarikan kesimpulan dengan proses pengumpulan data berbentuk siklus. Siklus dimulai dengan data yang terkumpul, kemudian direduksi, lalu peneliti menyajikan data tersebut, mengambil kesimpulan sementara untuk kemudian turun lagi ke lapangan. Kegiatan ini dilakukan sampai dengan peneliti yakin data telah jenuh dan dapat ditarik kesimpulan. Tahapan dalam analisis ini dimulai dengan tahapan reduksi data, yaitu merupakan proses seleksi, pemfokusan, penyederhanaan, mempertegas dan abstraksi data sehingga kesimpulan akhir dapat dilaksanakan. Tahap kedua adalah penyajian data, yaitu merangkai dan mengorganisasikan data. Tahap ketiga yaitu penarikan kesimpulan dengan cara memaknai informasi dengan melakukan pencatatan pernyataan, konfigurasi, arahan sebab akibat dan proposisi dari awal pengumpulan data (Sugiyono, 2010; Santoso, 2009; Moleong, 2004).

\section{HASIL DAN PEMBAHASAN \\ a. Hasil}

Berdasarkan temuan penelitian dapat dideskripsikan adanya adaptasi psikologis dalam pencapaian peran sebagai ibu dalam kehamilan yang terbagi menjadi tiga fase. Fase pertama di awal kehamilan, ibu hamil menerima kehamilannya setelah mengetahui hasil tes kehamilan yang positif, kemudian diperkuat dengan hasil kunjungan antenatal dengan bidan. Diagnosa kehamilan ini merupakan berita besar yang harus disampaikan kepada suami maupun keluarganya. Ibu hamil merasa senang dengan kehamilannya karena memang sudah direncanakan. Menurut pengungkapan delapan informan primer yang didukung data triangulasi menyatakan senang dengan kehamilannya dan memang sudah diharapkan dan direncakanan. 
"Nggak bisa ngucapin apa-apa. Pokoknya lemes nangis, nangis seneng, keluarga juga nggak mengira setelah 13 tahun akhirnya hamil".

Ibu Hamil 3, 32 th

"Ya seneng, karena memang pingin punya lagi".

Suami 2, 25 th

Mayoritas ibu hamil meyakini kehadiran janin dalam kandungan sejak ia mengetahui diagnosis hamil. Tujuh orang informan primer menyatakan merasakan kehadiran janin dalam kandungan sejak terlambat haid dan tes kehamilan.

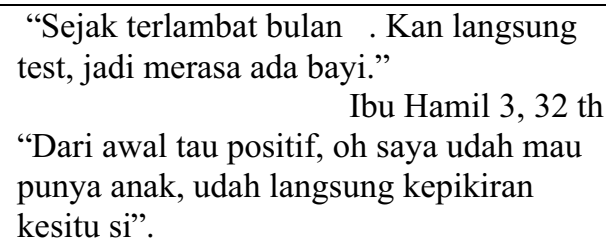

Ibu Hamil 1, 21 th

Ibu hamil merasakan kebahagiaan karena hamil, namun ia juga merasa tidak percaya jika akan memiliki anak. Sebagian ibu hamil mulai memikirkan perubahan yang timbul dan pengaruhnya terhadap kehidupan kesehariannya. Ia mulai memikirkan tentang keluhan yang timbul seperti mual, muntah, nyidam, keluhan capek akibat kehamilannya, dan perhatian dari suami dan keluarga. Tiga orang informan primer menyatakan tidak mengalami keluhan selama hamil, sedangkan empat orang informan primer menyatakan merasakan keluhan selama hamil.

"Saya mual- mual bu, sampai kapan si ini saya mual - mual, muntah terus lemes". Ibu Hamil 1, 21 th

Ibu merasa yakin telah menjadi seorang ibu dengan adanya janin dalam kandungan setelah merasakan gerakan janin yang menendang pada usia kehamilan empat sampai lima bulan. Ibu hamil memastikan hadirnya janin dengan melakukan pemeriksaan denyut jantung janin ketika melakukan kunjungan antenatal dengan bidan. Hasil indepth interview kepada triangulasi bidan didapatkan ibu merasakan gerakan janin dalam kandungan sejak usia kehamilan 16 minggu, janin sudah bergerak.

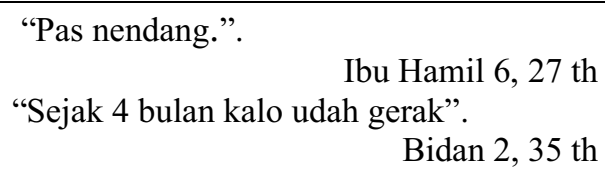

Ibu hamil mulai memiliki harapan terhadap janinnya agar tumbuh sehat, sempurna dan menjadi anak yang memenuhi kriteria yang baik sesuai ajaran agamanya. Pada fase ini, ibu hamil merasa siap menjadi seorang ibu, peran yang memang sudah ditunggu-tunggu sebelumnya. Bagi multigravida, ia juga mulai memikirkan bagaimana membagi peran terhadap anak sulungnya. Semua informan primer dan didukung data triangulasi menyatakan harapan dengan janin yang ada dalam kandungan sehat, sempurna, lahir normal.

"Yang dipikirkan ya semoga bayi nya
lahir sehat sempurna, bisa besarin anak,
nggak ada masalah sampai dia lahir, lahir
juga sehat wala'fiat, b isa besarin sampai
gede".
Ibu Hamil 1, 21 th
"Sehat, nggak ada kelainan apapun,
pinginnya cewe. Biar sepasang".
Ibu Hamil 7, 27 th
$\begin{aligned} & \text { "Ya mudah mudahan sehat tanpa ada suatu } \\ & \text { kekurangan apapun". } \\ & \text { Suami 2, 25 th }\end{aligned}$

Komunikasi antara ibu hamil dengan janin sering dilakukan pada fase ini, biasanya ibu hamil akan berbicara tentang kondisi yang 
ditemui dalam kesehariannya sampai dengan harapan-harapan terhadap janin dengan disertai mengelus-elus perutnya. Ibu hamil merasa mendapat feedback komunikasi dengan gerakan menendang yang dilakukan janin ketika berkomunikasi. Seperti hasil indepth interview didapatkan Semua informan primer menyatakan bentuk komunikasi yang dilakukan ibu dengan janin adalah dengan mengusap - usap perut sambil berbicara dengan janin.

"Diajak ngob rol, kalo lagi nendang -
nendang ya saya bilangin jangan nendang
- nendang. Sama anak saya kadang
ditanyain "dede lagi ngapain".".
Ibu Hamil 5, 27 th

Memasuki trimester ketiga kehamilannya, ibu hamil mulai fokus berfikir untuk kesejahteraan janinnya dan proses persalinannya. Ibu hamil rutin melakukan kunjungan antenatal dan meyakininya akan memperoleh informasi kepastian kesehatan janin yang dikandungnya serta memperoleh informasi seputar perkembangan kehamilan dan persiapan persalinan. Ketidaknyamanan dirasakan oleh ibu hamil sehubungan bertambah ukuran kandungannya. Sebagian ibu hamil merasa khawatir apakah ia mampu menjalani proses persalinan yang normal. Hasil indepth interview didapatkan, enam informan menyatakan merasa khawatir dengan kehamilannya karena bertambah usia kehamilannya, dalam menghadapi persalinan.

"Kepikiran persalinannya. Takut secar. tapi bismillah normal".

Ibu Hamil 8, 23 th
Ibu hamil mulai menyiapkan perlengkapan bayi, tempat persalinan, kendaraan yang diperlukan, donor dan biaya yang diperlukan untuk menyambut lahirnya janin.

\section{PEMBAHASAN}

Pencapaian peran sebagai seorang ibu dalam masa awal kehamilan dapat dideskripsikan dengan perasaan senang menerima kehamilannya, hasil penelitian ini sejalan dengan teori Reva Rubin yang dikenal dengan tahap antisipasi, yaitu merupakan tahapan sosial untuk penampilan peran yang diasumsikan pasangan dan berkaitan dengan fantasinya. Pada penelitian ini, ibu hamil telah menerima peran barunya ketika ia mulai mencari pembenaran kehamilannya dengan melakukan kunjungan antenatal ke bidan. Awal kehamilan ini juga muncul sikap ambivalensial yang merupakan ketidaksanggupan ibu dalam menerima perubahan kehamilannya. Mayoritas ibu hamil mulai berorientasi pada diri sendiri, sehubungan dengan keluhan yang muncul akibat proses kehamilannya. Hal ini merupakan kondisi yang normal dalam kehamilan. Kemampuan ibu dalam merasakan keadiran janin dalam kehidupannya dengan melihat hasil tes kehamilan pada penelitian ini, merupakan hal yang berbeda dengan teoriteori sebelumnya (Janiwarty dan Pieter, 2013). Mayoritas ibu hamil merasa semakin yakin dengan perannya sebagai seorang ibu, ketika dirasakan semakin keras gerakan janin dalam kandungannya (quickening). Mereka memasuki tahapan honeymoon dimana ibu 
ibu hamil mengasumsikan peran yang harus ditampilkan. Selain itu, kondisi fisik yang mulai stabil dan hilangnya keluhan mual muntah pada trimester kedua ini, membawa ibu hamil semakin fokus dengan kehadiran janin dalam kandungannya. Ibu hamil selalu berusaha mencari informasi tentang janinnya melalui pemeriksaan antenatal untuk meyakinkan kesejahteraannya. Hal inilah yang memberikan kekuatan seorang ibu dalam meyakini bahwa ada mahluk hidup lain yang terpisah dari dirinya yang harus diberikan perawatan selama kehamilan. Pada periode ini, ibu hamil akan memiliki kesadaran untuk memulai perubahan dalam fokusnya dari diri sendiri kepada bayi yang dikandung sebelumnya (Janiwarty dan Pieter, 2013; Leifer, 2015).

Pada trimester ketiga, ibu hamil mulai realistis dalam persiapan kelahiran bayinya. Periode ini merupakan penantian dengan penuh kewaspadaan. Ibu hamil akan mencari informasi tentang kesejahteraan bayinya lebih intensif. Ia akan semakin waspada dengan tanda-tanda persalinan, mengingat bayinya dapat lahir kapanpun dalam periode ini. Ibu hamil akan kembali merasakan ketidaknyamanan fisik pada trimester ini, selain itu timbul juga perasaan khawatir sehubungan dengan kesempurnaan fisik bayinya dan proses persalinannya. Hal ini sejalan dengan penelitian Rustikayanti (2016). Biasanya ibu hamil akan berusaha menghilangkan kekhawatirannya dengan menyibukan diri mencari informasi seputar persalinannya kepada lingkungan sosialnya maupun ke bidan. Segera setelah periode ini ibu hamil memasuki tahapan terminasi atau pengahiran masa kehamilan (Varney et al, 2007;
Janiwarty dan Pieter, 2013; Rustikayanti et al, 2016: 45-49).

Peran sebagai ibu dalam masa kehamilan dapat dicapai ketika ibu menjadi dekat dengan janin pada awal kehamilannya dan berlanjut menjadi dekat dengan bayinya pada kehamilan lanjut. Ekspresi kepuasan dan penghargaan ibu hamil dengan perannya selama masa kehamilan merupakan sikap ibu yang dapat dilihat oleh orang lain. Menurut Mercer, keberhasilan pencapaian peran ibu dalam kehamilan menjadi dasar dalam perananan ibu ketika 3-7 bulan setelah kelahiran (Janiwarty dan Pieter, 2013).

Pencapaian peran sebagi ibu bagi wanita hamil merupakan peristiwa sosial yang melibatkan suami, keluarga dan lingkungannya. Untuk mendukung pencapaian peran ini, ibu hamil sangat membutuhkan dukungan dari orang-orang terdekatnya dalam hubungan sosial. Terdapat hubungan positif yang sangat signifikan antara dukungan keluarga dengan proses adaptasi kehamilan. Inti penesuaian diri ibu hamil dapat dijelaskan dengan kemampuannya dalam menghadapi tekanan maupun konflik yang terjadi akibat perubahan fisik maupun psikologis selama kehamilan. Dukungan suami dan keluarga juga berpengaruh secara signifikan terhadap penurunan kecemasan ibu hamil dalam menghadapi proses persalinan. Ibu hamil trimester ketiga yang tidak tinggal serumah dengan suami karena pekerjaannya memiliki kategori kecemasan yang tinggi-sedang, dinbandingkan ibu hamil yang tinggal dengan suaminya rata-rata dalam kategori 
kecemasan sedang-rendah (Astuti et al, 2000: 84-95; Arifin et al, 2015: 1-6; Diani dan Susilawati, 2013: 1-11).

\section{SIMPULAN DAN SARAN}

\section{a. Simpulan}

Berdasarkan hasil penelitian dapat disimpulkan bahwa ibu hamil di Puskesmas Kembaran II telah mencapai perannya sebagai ibu sesuai tahapan pada trimester kehamilannya. Terdapat satu kondisi dimana ibu hamil terlalu cepat menerima kehadiran janinnya pada trimester pertama kehamilan dengan hanya melihat hasil pemeriksaan tes kehamilan, hal ini berbeda dengan teori sebelumnya.

\section{b.Saran}

Perubahan psikologis ibu dalam masa kehamilan untuk mencapai peran sebagai ibu merupakan kondisi yang kompleks. Dibutuhkan asuhan yang komprehensif dan berpusat pada kebutuhan seorang perempuan dari tenaga kesehatan. Selain itu, diperlukan dukungan positif dari suami, keluarga dan lingkungannya untuk pencapaian peran ini.

\section{DAFTAR PUSTAKA}

Arifin A; Kundre R; Rompas S 2015, 'Hubungan dukungan keluarga dengan kecemasan ibu hamil menghadapi proses persalinan di puskesmas budilatama kecamatan gadung kabupaten buol propinsi sulawesi tengah', eJournal Keperawatan (e-Kp), vol 3 (2), pp. 16.

Astuti AB; Santosa SW; Utami MS 2000, 'Hubungan antara dukungan keluarga dengan penyesuain diri perempuan pada kehamilan pertama', Jurnal Psikologi, vol 2, pp. 84-95.

Bobak IM; Lowdermilk DL; Jensen MD 2005, Buku Ajar Keperawatan Maternitas (Maternity Nursing), 4th edn, EGC, Jakarta.
Burns ER; Farr SL; Howards PP 2015, 'Stressfull Life Events Experienced by Women in the Year before Their Infants' Birth-United States, 2000-2010', MMWR, vol 64(9), pp. 247-251.

Carmichael SL; Ma C; Tinker S; Rasmussen SA; Shaw GM; and The National Birth Defects Prevention Stud 2014, 'Maternal Stressors and Social Support as risk for Delivering Babies with Structural Defect', D. Pediatr Perinat Epidemiol, vol 28(4), pp. 338-344.

Cresswell, John W 2009, Research Design, Pendekatan Penelitian Kualitatif, Kuantitatif, dan Mixed, Pustaka Pelajar, Yogyakarta.

Diani LPP; Susilawati LKPA 2013, 'Pengaruh dukungan suami terhadap istri yang mengalami kecemasan pada kehamilan trimester ketiga di kabupaten gianyar ', Jurnal Psikologi Udayana, vol 1(1), pp. 111.

Janiwarty B; Pieter HZ 2013, Pendidikan Psikologi untuk Bidan; Teori dan Penerapannya, Rapha Publising, Yogyakarta.

Lancaster CA; Gold KJ; Flyn HA; Yoo H; Marcus SM; Davis MM 2010, 'Risk Factor for Depressive symptoms during Pregnancy; A systematic Review', Am J Obstet Gynecol Neonatal Nurs, vol 202, pp. 5-14.

Leifer, G 2015, Introduction to Maternity and Pediatric Nursing, 7th edn, Elsevier, Canada.

Modh C, Ludgren I, Bergbon I 2011, 'First Time Pregnan Women's Experiences in early Pregnancy', Int J Qualitative Stud Health Well-being, vol 1, pp. 1-11.

Moleong, L 2004, Metodologi Penelitian Kualitatif, ROSDA, Bandung.

Rustikayanti RN; Kartika I; Herawati Y 2016, 'Perubahan Psikologis pada ibu hamil trimester III', Seajom, vol 2(1), p. 45-49.

Santoso, G 2009, Tehnik Penulisan Laporan Penelitian Kualitatif, LPSP3UI, Jakarta. Sugiyono 2010, Metodologi Penelitian Kuantitatif Kulaitatif dan $R \& D$, Alfabeta, Bandung. 
Underdown A, Barlow J 2012, 'Maternal Emotional Wellbeing and Infant Development; A Good Practice Guide for Midwives', The Royal college of Midwives, London, http//:www.rcm.org.uk. viewed Dec 2017.

Varney H; Kriebs JM; Gegor CL 2007, Buku Ajar Asuhan Kebidanan (Varney's Midwifery), 4th edn, EGC, Jakarta. 